\title{
Harold Austen Oberman
}

I n a masterful display of the grace, balance, and precision for which he was so well known throughout his life, Harold (Hal) Austen Oberman, a longtime member of the University of Michigan Medical School faculty, died peacefully after a long struggle with cancer, on his 72nd birthday. Hal was known internationally for his contributions to the fields of both anatomic and clinical pathology, a rare achievement in the highly specialized field of pathology. He took equal pride and honor in counseling individual patients and their families as they faced difficult decisions regarding diagnosis and treatment.

Hal received an $A B$ from the University of Omaha (Nebraska) in 1953 and an MD (cum laude) from the University of Nebraska College of Medicine in 1956. He completed residency training in anatomic and clinical pathology at the University of Michigan Medical School in 1960. He served in the US Army Medical Corps from 1961 to 1963 as a captain and was appointed Assistant to the Chief of the Pathology Service at Walter Reed Army General Hospital in Washington, DC. After completing military service, he returned to the faculty of the Department of Pathology at the University of Michigan. Hal remained at the University of Michigan as a full professor of pathology until his retirement in 2001. He served as Head of the Section of Clinical Pathology from 1981 through 1987 and as Co-Director of the Division of Clinical Pathology through 1991. He also served as Director of the Blood Bank from 1964 to 2001. He was named Active Emeritus Professor in 2001.

Dr. Oberman was nationally and internationally recognized as one of the country's preeminent experts in the area of blood banking and blood transfusion, serving as a member of the Medical Advisory Committee for the American National Red Cross, the Advisory Committee to the Division of Blood Diseases and Resources for the National Heart and Lung Institute, and the Transfusion Reactions Practice Guidelines Task Force for the College of American Pathologists and the Panel on Universal Leukoreduction of Blood Components for the University Health System Consortium. He also achieved recognition as one of the leading authorities in the diagnosis of breast pathology, serving as an organizing member of the Breast Care Center at the University of Michigan and as a member of the Breast Cancer Task Force and Advisory Committee for the Michigan Department of Public Health. For many years,

TRANSFUSION 2005;45:283-284.

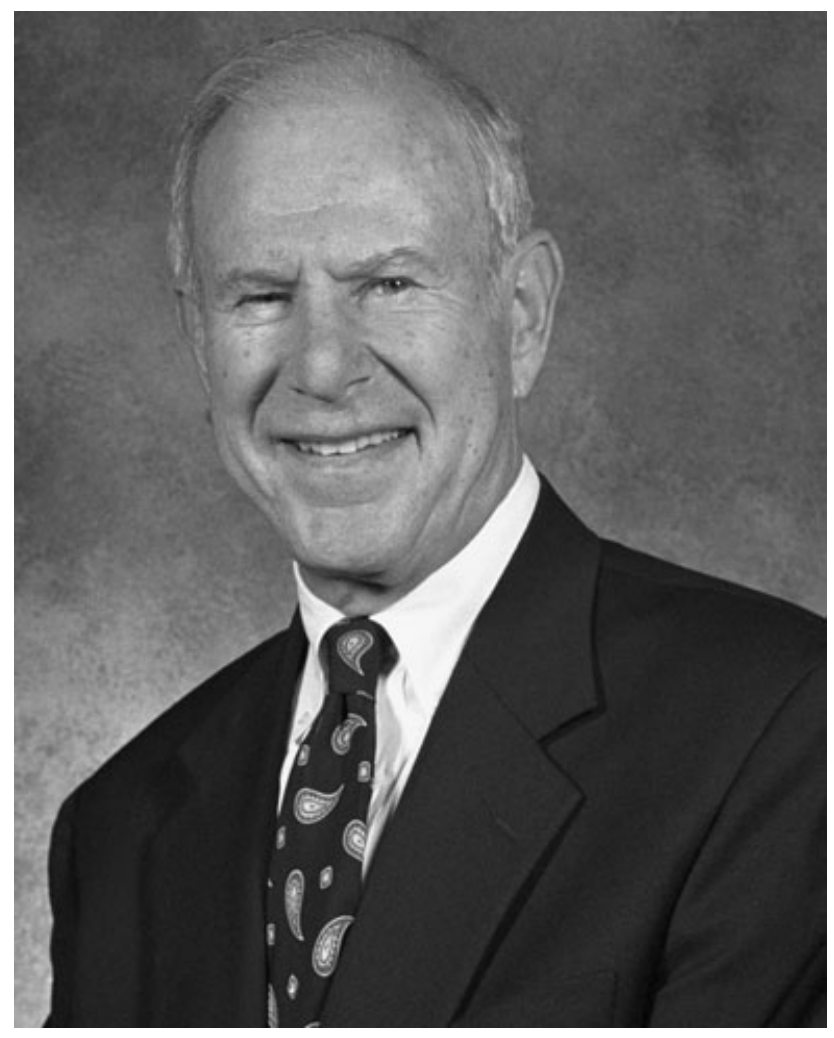

he served as the final arbiter for the diagnosis of the most difficult cases that were submitted to him from around the country for his opinion. His expertise in both anatomic pathology and clinical pathology was viewed as quite remarkable, even among his peers, and represents a gold standard that will never be repeated in academic pathology.

Hal was recognized as an outstanding teacher, receiving numerous awards including the Elizabeth Crosby Award (outstanding professor in basic sciences) from the University of Michigan Medical School and Excellence in Teaching Award from medical students at the University of Michigan Medical School. He had a profound influence on thousands of medical students and residents in pathology who mastered the subtleties of disease through his eloquent whole-class lectures, more intimate sophomore pathology laboratories, and one-on-one interactions. He reveled in the role of teacher and mentor; he and his wife, Marylen, frequently invited all of the students from his laboratory to his home for a social gathering to mark the end of the school term. 
He was also recognized for his achievements by numerous other awards including the John Elliott Memorial Award from the AABB; the Founders Award from the Michigan Association of Blood Banks; and the Distinguished Alumnus Award, University of Nebraska College of Medicine and was named as one of the 2000 Best Doctors in America in 1992, 1995, and 1997. He served as an editor for several journals including TRANSFUSION, the American Journal of Surgical Pathology, Modern Pathology, and the American Journal of Clinical Pathology; was an invited speaker at numerous national and international meetings; and authored approximately 200 publications including articles and abstracts in scientific journals and book chapters.

A man with a generous and warm heart, Hal found great pleasure in the day-to-day joys of life in Ann Arbor. He loved the fall, for both its poignant reminder of the fleeting beauty and also for the vibrancy of Michigan football games (for which he insisted on arriving in time to hear "band take the field"). The son of the late Lillian and Isidore Oberman, Hal was raised with a passion for poetry, music, learning, and chocolate. He will be remembered with gratitude and blessing by Marylen Segel Oberman, his wife of more than 45 years; his children, Michelle, Debra, and Jeffrey; his brother Robert; and his grandchildren, sons-in-laws, sisters-in-laws, brother-in-law, nieces, nephews, and generations of pathology residents, medical students, and friends.

Robertson D. Davenport W. John Judd Department of Pathology University of Michigan Ann Arbor, MI 